\title{
Conservative Treatment of Idiopathic Scoliosis through the Global Postural Re-Education
}

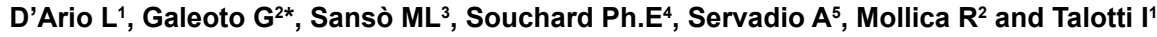 \\ ${ }^{1}$ Physiotherapist freelancer Naples, Italy \\ ${ }^{2}$ Department of Science anatomical, histological, forensic and musculoskeletal system University "Sapienza" of Rome, Italy \\ ${ }^{3}$ Orthopedics and Traumatology AORN Santobono Pausilipon of Naples, Italy \\ ${ }^{4}$ Physiotherapist, creator of R.P.G., France \\ ${ }^{5}$ University of Rome Tor Vergata, Italy
}

\begin{abstract}
The Scoliosis Research Society defines scoliosis as a deformity in the frontal plane with a Cobb angle greater than $10^{\circ}$.

Our case report shows a seven year's old patient suffering from idiopathic scoliosis related to a myogenic torticollis from birth by hematoma of Sternocleidomastoid (SCM) $\mathrm{dx}$.

The patient through the rehabilitation treatment with the Global Postural Re-education (GPR) with frequency of a weekly session of 60 minutes, for a period of 14 months, showed a significant improvement of the postural, the reduction in Cobb degrees of scoliosis and lordosis and quality of life. However, it appears necessary to continue studying conservative rehabilitation methods effective for idiopathic scoliosis.
\end{abstract}

Keywords: Scoliosis; Global postural re-education; Coob; Conservative treatment

\section{Introduction}

Idiopathic Scoliosis (IS) is a complex structural deformity of the spine that twists on the three planes of space [1-4]. According to definition idiopatic scoliosis is a multi-factorial disease.

From a etiopathogenic point of view therefore the spinal deformity caused by idiopathic scoliosis can be defined as the sign of a complex syndrome with a multifactorial ethology $[5,6]$.

This sindrome shows itself almost always with a deformity, but deeper investigations may show sub-clinical significant signs [3,6-8].

Idiopathic Scoliosis (IS) can occur at any time during childhood and adolescence. It is more common in periods of strong growth between 6 and 24 months, between 5 and 8 years, and between 11 and 14 years of life. The rate of development of the spinal curve changes more rapidly at the beginning of puberty [9]

The Scoliosis Research Society [1,10] defines scoliosis as a deformity in the frontal plane with a Cobb angle greater than $10^{\circ}$.

Based on this data, many papers published on the effectiveness of conservative treatment of scoliosis (physiotherapy, plaster braces, braces) use as a parameter modification of Cobb. This is intended to be reviewed in the future considering the importance of the vertebral rotation, evaluated both radio graphically and clinically [11].

The idiopathic scoliosis may be classified differently $[1,4,12]$ according to the initial localization of deformities: scoliosis thoracic, thoracolumbar, lumbar, double curve, and according to the age of onset: childhood, adolescence and youth.

Even idiopatic scoliosis patient belongs to who ICIDH classification [13] under the voices "disease" and "disability".

These definitions have been updated by WHO in the new classification ICF [13] as impairment, reduction of activity and restriction of participation, which can also be applied to the patient with idiopathic scoliosis.
There are many rehabilitation treatments already validated for the conservative treatment of idiopathic scoliosis [13-15].

\section{Case Report}

In September 2013, a seven year's old girl during a orthopaedic visit showed results of myogenic torticollis hematoma of the right SCM deviation broad spine cervical-back injury, with mild and initial rotation of the somites, asymmetry of the shoulder girdle left with the presence of scapular winging. At the time of the specialist assessment (September 2013) the radiographic situation was as follows: in the frontal plane curve D4-L2 $20^{\circ}$ Cobb, sagittal cervical lordosis of $52^{\circ}$ Cobb, lumbar $36^{\circ}$ Cobb.

The orthopaedic surgeon prescribed a course of Global Postural Reeducation (GPR) according to the method of Ph. E. Souchard [16,17]. The personal history at birth (spontaneous delivery at 41 weeks) showed a weight of $4100 \mathrm{~kg}$, a length of $52 \mathrm{~cm}$, a head circumference of $36.5 \mathrm{~cm}$. The first check at the age of 15-30 days showed an attitude of right tilt of the head and the ultrasound showed a myogenic torticollis; the patient performed rehabilitation treatment from 15 days of life up to four years. Since September 2013, the patient underwent a functional evaluation and a cycle of Global Postural Re-education for one weekly session lasting one-hour / day (Figures 1 and 2).

For the assessment of pain and activities of daily life were administered at each assessment, the VAS and SF-3. This allowed the evaluator to verify the improvements during the year of treatment.

*Corresponding author: Giovanni Galeoto, Department of Science Anatomical Histological, Forensic and Musculoskeletal System University of Rome, Italy, Tel: +393271431083; E-mail: usifi.aifilazio@gmail.com

Received September 09, 2015; Accepted November 05, 2015; Published November 12, 2015

Citation: D'Ario L, Galeoto G, Sansò ML, Souchard E, Servadio A et al. (2015) Conservative Treatment of Idiopathic Scoliosis through the Global Postural ReEducation. J Clin Case Rep 5: 630. doi:10.4172/2165-7920.1000630

Copyright: $\odot 2015$ D'Ario L, et al. This is an open-access article distributed under the terms of the Creative Commons Attribution License, which permits unrestricted use, distribution, and reproduction in any medium, provided the original author and source are credited. 


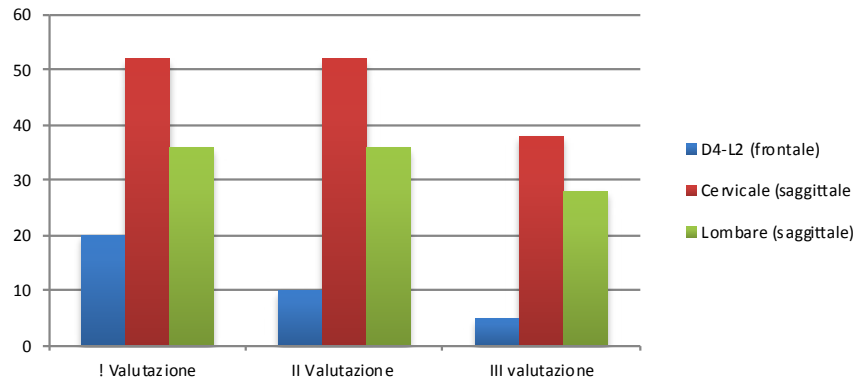

Figure 1: COBB degree evaluation.
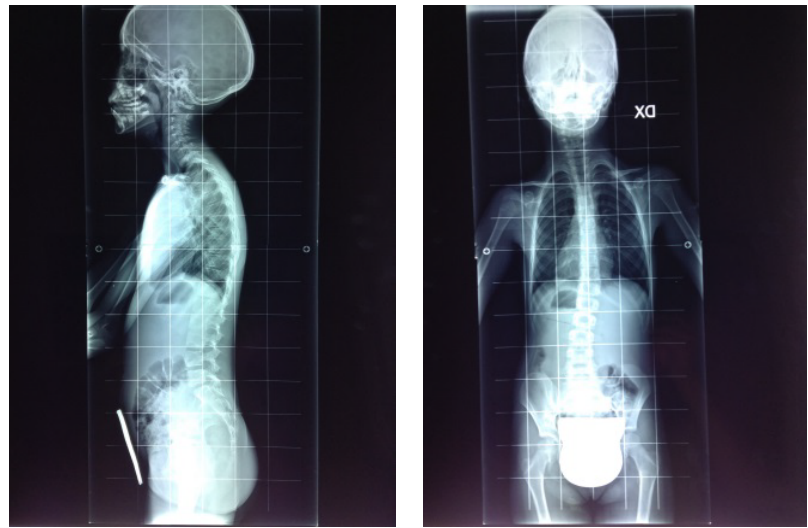

Figure 2: Radiographic evaluation - 2013

The physiotherapeutic treatment consists of individual sessions with the presence of the physiotherapist, and sessions of self-correction through the self-posture, that the patient must perform at home.

At the first orthopaedic control held in January 2014 (follow-up 4 months) the patient was improved according radiography (scoliosis D4-L2 10 degrees Cobb); it appeared clinically improved the set postural general and in particular the ratio skull-neck. During the second orthopaedic control held in March 2014 (follow-up seven months) the clinical and radiographic situation was unchanged and then it was requested to continue with the same method of rehabilitation (GPR).

At last check orthopaedic November 2014 (follow-up 14 months) the patient showed good curve correction Front (scoliosis D4-L2 5 degrees Cobb) (Figure 1) and a residual asymmetry of the shoulder girdle. On sagittal plane it was reduced the hyper-lordosis lumbar but greatly reduced the cervical (cervical 38th, lumbar $28^{\circ}$ ) (Figures 3-5).

Score analisis of the SF-36 shown an improvement of the 6\% regard physical activity, an improvement of the $12 \%$ physical pain and an inprovement of the $25 \%$ general health. Indeed patient used to report to be completely limitless abaut physical activity.

The evaluation of health status showed a significant improvement in the perception of the general health and this allows us to state that the rehabilitation program has motivated and improved the health of the patient.

\section{Discussion}

The treatment of IS is a course of treatment and prevention of the aggravation [3-5]. An idiopatic scoliosis under $20^{\circ} \mathrm{Cobb}$ is considered exclusively a physiotherapic treatment [17]. This therapeutic phase is traditionally defined as "free treatment" (exercises with medical follow) and concerns the so-called minor scoliosis (normally below $20^{\circ} \mathrm{Cobb}$ ).

Idiopatic scoliosis prevention has to always be treated by physioterapists because a minor scoliosis may lead into a major scoliosis $[12,13]$.

The prevention mainly consists of specific exercises of physiotherapy: it is a work aimed at improving the capacity of neuromotor, adapted and controlled on the basis of the pathology and the individual characteristics of the individual patient. The whole exercise is aimed at improving the specific skills of the individual (balance, coordination and eye-hand control) respecting the balance of biomechanics (the action is on three floors of the space).
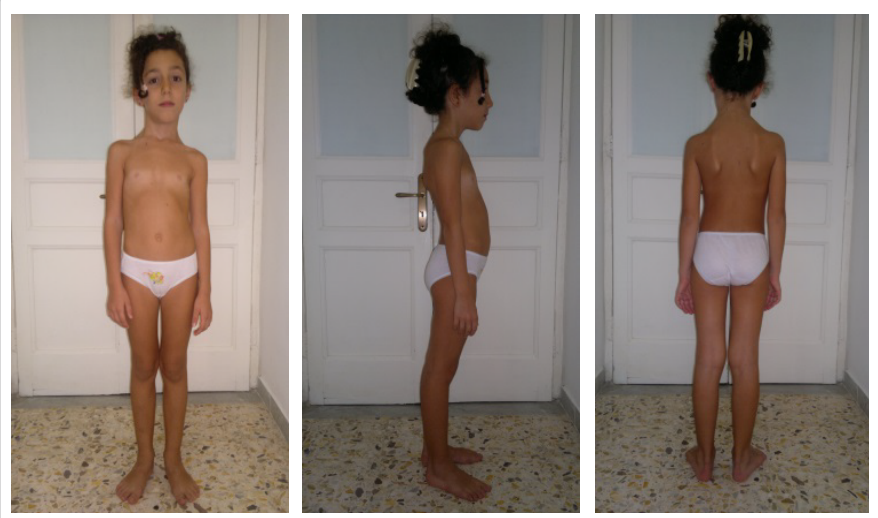

Figure 3: Three projections static functional evaluation - Sept. 2013.
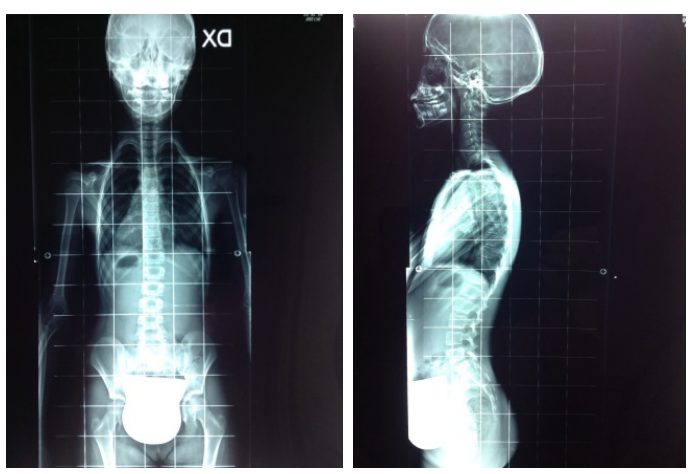

Figure 4: Radiographic evaluation - Nov. 2014.
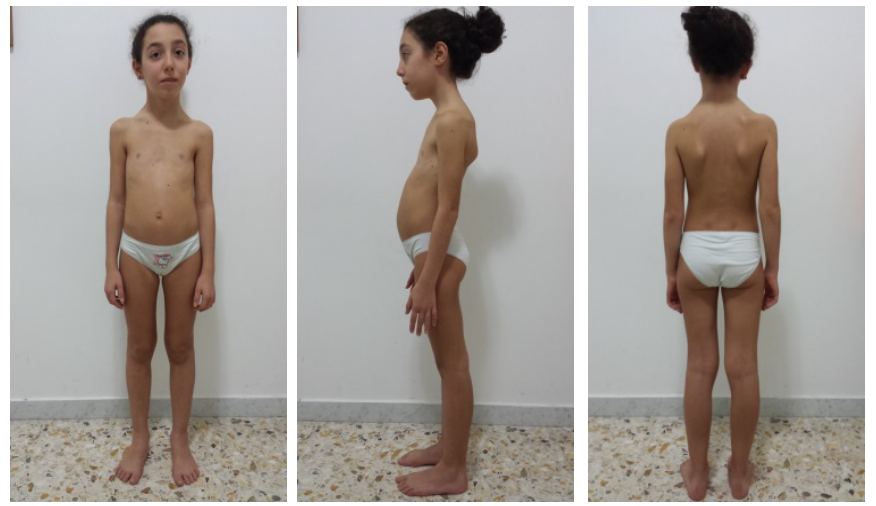

Figure 5: Functional evaluation - Dec. 2014. 
Citation: D'Ario L, Galeoto G, Sansò ML, Souchard E, Servadio A et al. (2015) Conservative Treatment of Idiopathic Scoliosis through the Global Postural Re-Education. J Clin Case Rep 5: 630. doi:10.4172/2165-7920.1000630

Treatment with Global Postural Re-education showed great improvements of daily life, of the postural and balance sheet radiographic Cobb degrees of scoliosis in spite of the pre-pubertal and high upgradeability [10].

It was also evident in an improvement in the sagittal plane. The results of this case report can make a contribution to continue in the direction of this method and physiotherapy for further investigation around the physiotherapy in the IS and the GPR in IS with more houses and clinical studies. "The authors declare that there is no conflict of interests regarding the publication of this paper".

\section{References}

1. Stagnara P (1985) Les déformations du rachis. Paris: Masson, Perdriolle R. La scoliose: son étude tridimensionnelle. Paris: Maloine France.

2. Selleri U, Negrini S (1999) The rehabilitation of patients with idiopathic scoliosis Treaty of Rehabilitation Medicine ,Physical Medicine and Rehabilitation Napoli: Idelson Gnocchi 1123-47 France.

3. Negrini S, Aulisa AG, Aulisa L, Circo AB, de Mauroy JC, et al. (2012) 2011 SOSORT guidelines: Orthopaedic and Rehabilitation treatment of idiopathic scoliosis during growth. Scoliosis 7: 3 .

4. Nachemson A, Sahlstrand T (1977) Etiologic factors in adolescent idiopathic scoliosis. Spine 2:176-184

5. Moen KY, Nachemson AL (1999) Treatment of scoliosis. An historical perspective. Spine (Phila Pa 1976) 24: 2570-2575.

6. Machida M1 (1999) Cause of idiopathic scoliosis. Spine (Phila Pa 1976) 24 2576-2583.
7. Sibilla P, Cesarani A Negrini, Atanasio S, Alpini S, et al. (1999) Stepping coordination in scoliosis evaluated by the mean of craniocorpography. Vestibular and Neural Front 39-42.

8. Lonstein JE, Carlson JM (1984) The prediction of curve progression in untreated idiopathic scoliosis during growth. J Bone Joint Surg Am 66: 1061-1071.

9. Weinstein SL (1999) Natural history. Spine (Phila Pa 1976) 24: 2592-2600.

10. World Health Organization (1980) ICIDH - International Classification of Impairment, Disability and Handicap World Health Organization, Geneva, Switzerland.

11. World Health Organization (2001) ICF - International Classification of Functioning, Disability and Health. Geneva, World Health Organization.

12. Negrini A, Sibilla $P$, Negrini $S$ (1992) The physiotherapy in the treatment of scoliosis: new methodological guidelines. Rehabilitation Today. 9: 11-15

13. Negrini S, Antonini G, Carabalona R, Minozzi S (2003) Physical exercises as a treatment for adolescent idiopathic scoliosis. A systematic review. Pediatr Rehabil 6: 227-235.

14. Antonini G, Negrini S, Carabalona R, Marinoni EC (2000) The upgradeability of idiopathic scoliosis : meta-analysis. Spinal deformities : state of the art Vigevano : Study Group of Scoliosis 129-148.

15. Teodori RM, Negri JR, Cruz MC, Marques AP (2011) Global Postural Reeducation: a literature review. Rev Bras Fisioter 15: 185-189.

16. Fortin C, Feldman DE, Tanaka C, Houde M, Labelle H (2012) Inter-rater reliability of the evaluation of muscular chains associated with posture alterations in scoliosis. BMC Musculoskelet Disord 13: 80.

17. Negrini A, Negrini MG, Donzelli S, Romano M, Zaina F, et al. (2015) ScoliosisSpecific exercises can reduce the progression of severe curves in adult idiopathic scoliosis: a long-term cohort study. Scoliosis 10: 20. 